\title{
MUTU PELAYANAN STANDAR PELAYANAN MINIMAL (SPM) PENDAFTARAN PASIEN DI TEMPAT PENDAFTARAN PASIEN RAWAT JALAN (TPPRJ) PUSKESMAS NGALIYAN KOTA SEMARANG
}

\section{QUALITY OF MINIMUM SERVICE STANDARDS (SPM) PATIENT REGISTRATION IN PLACE REGISTRATION FOR OUTPATIENT (TPPRJ) PUKESMAS NGALIYAN KOTA SEMARANG}

\author{
Faik Agiwahyuanto ${ }^{1 *}$, Ferdiansyah Hari Noegroho ${ }^{2}$
}

\begin{abstract}
${ }^{* 1}$ Dosen Program Studi D-3 Rekam Medis dan Informasi Kesehatan, Fakultas Kesehatan, Universitas Dian Nuswantoro, Jalan Nakula No. 5-11 Semarang, Jawa Tengah, email: faik.agiwahyuanto@dsn.dinus.ac.id, Indonesia

${ }^{2}$ Alumni Program Studi D-3 Rekam Medis dan Informasi Kesehatan, Fakultas Kesehatan, Universitas Dian Nuswantoro, Jalan Nakula No. 5-11 Semarang, Jawa Tengah, email: ferdiantup123@gmail.com, Indonesia
\end{abstract}

\begin{abstract}
Background: Minimum Service Standards (SPM) in outpatient services at the Ngaliyan Community Health Center reads the standard time to serve old patients ie 5 minutes while patients are only 7 minutes. Based on the initial survey of 10 outpatients in the Ngaliyan Health Center divided into 5 old patients and 5 new patients, it was found that on average the officers served the old patients ie 18 minutes 17 seconds and the new patients were 18 minutes 32 seconds.

Objective: This study aims to analyze the service quality minimum (SPM) of TPPRJ inpatient registration at the Ngaliyan Health Center Semarang City.

Methods: This study used an observational analytic research design with cross-sectional approach at Ngaliyan Public Health Center Semarang City. The sampling technique used purposive sampling with total sample are 20 respondents. Analysis data using univariate with percentage.

Result: The results showed that in 1st stage average time service old patients is 6 minutes 13 seconds and new patients is 12 minutes 6 seconds. In 2 nd stage average time service old patients is 11 minutes 3 seconds and new patients is 12 minutes 6 seconds.

Conclusion: SPM service quality of inpatients registration influenced by inpatient waiting time.
\end{abstract}

Keywords: SPM, Service Quality, TPPRJ

\section{PENDAHULUAN}

Puskesmas adalah Unit Pelaksana

Teknis Daerah (UPTD) dinas kesehatan

kabupaten/kota. Tugas dan fungsinya

mengacu pada kebijakan pembangunan

kesehatan Pemerintah Daerah

Kabupaten/Kota bersangkutan dalam

Rencana Pembangunan Jangka Menengah

Daerah (RPJMD) dan Rencana Lima

Tahunan dinas kesehatan kabupaten/kota. ${ }^{1}$

Puskesmas sebagai penyelenggara upaya

kesehatan tingkat pertama bertanggung jawab memberikan pelayanan kesehatan seluruh masyarakat secara administratif berdomisili di wilayah kerjanya. Adanya Puskesmas diharapkan masyarakat memperoleh pelayanan kesehatan bermutu dengan akses termudah dan biaya terjangkau. $^{2}$

Mutu pelayanan kesehatan puskesmas adalah tingkat pelayanan kesehatan yang sempurnayang diselenggarakan sesuai kode etik dan standar pelayanan yang sudah ditetapkan, 
sehingga menimbulkan kepuasan setiap pasien. ${ }^{3}$ Waktu tunggu yaitu waktu yang digunakan pasien mendapatkan pelayanan kesehatan dari tempat pendaftaran sampai masuk ruang pemeriksaan dokter. ${ }^{4}$

Waktu tunggu di Indonesia ditetapkan oleh Kementerian Kesehatan (Kemenkes) melalui standar pelayanan minimalberdasar Kemenkes Nomor 129/Menkes/SK/II/2008. Setiap puskesmas wajib mengikuti standar pelayanan minimal waktu tunggu. Kategori jarak waktu tunggu dan waktu periksa yang diperkirakan mampu memuaskan atau kurang memuaskan pasien yaitu saat pasien datang mulai mendaftar ke loket, antri, menunggu panggilan ke poli untuk dianamnesis dan diperiksa oleh dokter, perawat, atau bidan $>90$ menit (kategori lama), 30-60 menit (kategori sedang) dan $\leq$ 30 menit (kategori cepat). Pelayanan minimal di rawat jalan ialah $\leq 60$ menit. $^{1}$

$$
\text { Bagian terpenting pelayanan }
$$

kesehatan adalah tersedia dan dipatuhinya standar.Pelayanan kesehatan yang bermutu apabila dilaksanakan sesuai dengan standar yang ada. Standar adalah tingkat ketercapaian ideal yang diinginkan dan tujuan yang ingin dicapai. Standar Pelayanan Minimal (SPM) merupakan ketentuan jenis dan mutu pelayanan dasar.SPM adalah urusan wajib daerah yang berhak diperoleh setiap warga secara minimal. Salah satu Standar Pelayanan Minimal (SPM) untuk peningkatan mutu pelayanan adalah standar waktu tunggu pelayanan pasien rawat jalan. ${ }^{5}$
SPM Bidang Kesehatan mengalami perubahan yang cukup mendasar dari SPM sebelumnya yang semula dilandaskan Permenkes RI Nomor 43 Tahun 2016 tentang SPM Bidang Kesehatan menjadi didasarkan Permenkes RI Nomor 4 Tahun 2019 tentang Standar Teknis Pemenuhan Mutu Pelayanan Dasar Pada SPM Bidang Kesehatan. SPM dapat menjadi landasan Pemerintah Pusat dalam pemberian insentif, disinsentif, dan sanksi administrasi Kepala Daerah, maupun dalam perumusan kebijakan nasional dengan memonitoring potensi daerah. ${ }^{6}$

\section{Menurut Permenkes 269/2008} tentang rekam medis pasal 1 ayat 1 rekam medis adalah berkas yang berisi catatan dan dokumen tentang identitas pasien, pemeriksaan, pengobatan, tindakan, dan pelayanan lain yang telah diberikan kepada pasien. Rekam Medis mempunyai nilai informasi yang bertanggung jawab dan setiap unit-unit terkait perlu memberikan dukungan pada unit rekam medis.Salah satu dukungan unit rawat jalan kepada rekam medis dapat dilakukan dengan cepat. Dengan demikian tujuan unit rekam medis dalam menyelenggarakan proses pengelolaan dan penyimpanan dapat berjalan dengan baik. ${ }^{7}$

Unit Rekam Medis di puskesmas terdiri atas subunit-subunit rekam medis yang lengkap, seperti yang diselenggarakan di rumah sakit. Salah satu subunit yang diselenggarakan di puskesmas yaitu bagian pencatatan atau perekam data rekam medis yang terdiri atas tempat atau loket 
pendaftaran pasien, baik itu rawat jalan, rawat inap, maupun gawat darurat. Pelayanan Rawat Jalan adalah rangkaian kegiatan pelayanan medis yang berkaitan dengan kegiatan poliklinik atau ruang periksa. Komponen pelayanan Tempat Pendaftaran Pasien Rawat Jalan (TPPRJ) mulai dari pasien datang hingga pasien menunggu dokter di ruang periksa dokter. Fungsi utama dari loket pendaftaran pasien itu sendiri yaitu sebagai tempat melayaninya pendaftaran pasien, baik itu pasien baru maupun pasien lama.

Berdasarkan survei awal di Puskesmas Ngaliyan di bagian pendaftaran TPPRJ diambil 10 responden pasien TPPRJ dan dilakukan penelitian, bahwa terdapat 5 pasien mengatakan pelayanan TPPRJ yang diberikan tidak puas dengan alasan waktu menunggu pendaftaran TPPRJ lama, 4 pasien mengatakan cukup puas dengan alasan waktu menunggu pendaftaran TPPRJ tidak begitu lama, dan 1 pasien mengatakan pelayanan TPPRJ yang diberikan puas dengan alasan petugas pendaftaran TPPRJ ramah dan waktu menunggu pendaftaran TPPRJ tidak lama serta kondisi tempat menunggu pasien nyaman, dengan rata-rata waktu melayani pasien lama yaitu 18 menit 17 detik dan rata-rata waktu melayani pasien baru yaitu 18 menit 32 detik. Hal tersebut sebenarnya sudah masuk kategori pelayanan yang diberikan lama, karena Standar Pelayanan Minimal (SPM) yang ditetapkan di bagian TPPRJ di Puskesmas Ngaliyan kurang lebih 5 menit untuk pasien lama dan kurang lebih 7 menit untuk pasien baru.

Penyebab utama waktu pelayanan pasien yang lama yaitu lamanya waktu pendaftaran di loket, terbatasnya jumlah dokter, pasien yang banyak, dan terbatasnya staf pelayanan kesehatan lainnya. ${ }^{8}$ Waktu tunggu di rawat jalan kurang dari 60 menit, kepuasan pelanggan/pasien di atas 90\%. Waktu tunggu merupakan masalah yang sering menimbulkan keluhan dari pasien di beberapa fasilitas kesehatan. Pasien sangat memperhatikan waktu tunggu pelayanan. Waktu tunggu yang panjang secara konsisten dapat menyebabkan ketidak puasan dari pasien. Lama waktu tunggu memberikan pengaruh yang besar kepada pasien karena berhubungan dengan mutu pelayanan atau pengobatan sehingga harus diperhatikan oleh penentu kebijakan. ${ }^{2}$

Seiring peningkatan tingkat pendidikan dan sosial-ekonomi masyarakat, maka tuntutan terhadap pelayanan kesehatan semakin meningkat. Persaingan yang terjadi tidak hanya dari sisi teknologi pemeriksaan, akan tetapi persaingan yang lebih berat yaitu persaingan dalam pelayanan kesehatan yang berkualitas. ${ }^{9} \quad$ Institusi kesehatan harus memperhatikan kualitas pelayanannya termasuk waktu tunggu pasien karena dapat berpengaruh terhadap mutu pelayanan pasien.

Berdasarkan permasalahan diatas, peneliti tertarik untuk membahas lebih mendalam masalah tersebut dengan judul 
"Mutu Pelayanan Standar Pelayanan Minimal (SPM) Pendaftaran Pasien Di Tempat Pendaftaran Pasien Rawat Jalan (TPPRJ) Puskesmas Ngaliyan Kota Semarang".

\section{BAHAN DAN CARA PENELITIAN}

Desain penelitian adalah metode observasi dengan survei analitik pendekatan cross sectional yaitu peneliti mempelajari tentang waktu tunggu dan mutu pelayananan dengan melakukan pengukuran pada saat yang bersamaan dan dilakukan satu kali saja. ${ }^{10}$ Cara Pengambilan Sampel dilakukan dengan cara purposive sampling yakni pengambilan sampel berdasarkan kriteria inklusi yang telah ditetapkan oleh peneliti yaitu pasien rawat jalan baru dan lama di Puskesmas Ngaliyan Kota Semarang. Jumlah sampel dalam penelitian ini adalah 20 responden. Alat ukur menghitung waktu pasien dengan menggunakan stopwatch. Cara mengaplikasikannya yaitu peneliti melakukan kegiatan daftar tilik terhadap petugas saat melayani pasien lama dan disaat itu juga peneliti mengukur waktu pasien lama dilayani dengan menggunakan stopwatch selama 12 hari. Analisis data univariat dilakukan terhadap distribusi frekuensi persentase tiap-tiap variabel penelitian.

\section{HASIL DAN PEMBAHASAN}

Tabel 1 merupakan waktu pasien lama dilayani di pendaftaran rawat jalan sesi
1. Hasilnya rata-rata waktu pendaftaran pasien lama 6.13 menit.

Tabel 1. Waktu Pasien Lama Dilayani Di Pendaftaran Rawat Jalan Sesi 1 ( $n=14)$

\begin{tabular}{ccc}
\hline No & $\begin{array}{c}\text { Responden } \\
\text { (Pasien Lama) }\end{array}$ & $\begin{array}{c}\text { Waktu dilayani } \\
\text { di TPPRJ }\end{array}$ \\
\hline 1 & Responden 1 & 6.05 \\
2 & Responden 2 & 5.15 \\
3 & Responden 3 & 7.52 \\
4 & Responden 4 & 7.37 \\
5 & Responden 5 & 5.40 \\
6 & Responden 6 & 7.18 \\
7 & Responden 7 & 6.20 \\
8 & Responden 8 & 5.48 \\
9 & Responden 9 & 6.10 \\
10 & Responden 10 & 6.39 \\
11 & Responden 11 & 5.59 \\
12 & Responden 12 & 4.07 \\
13 & Responden 13 & 9.50 \\
14 & Responden 14 & 7.40 \\
\hline Rata-rata waktu & 6.13 \\
pelayanan pasien lama & \\
\hline Sur
\end{tabular}

Sumber: Data Primer 2019.

Tabel 2 merupakan waktu pasien baru dilayani di pendaftaran rawat jalan sesi 1. Hasilnya rata-rata waktu pendaftaran pasien lama 12.06 menit.

\begin{tabular}{ccc}
\multicolumn{2}{c}{$\begin{array}{c}\text { Tabel } \\
\text { Pendaftaran Rawat Jalan Sesi 1 }(\mathbf{n = 6 )}\end{array}$} \\
\hline No & $\begin{array}{c}\text { Responden } \\
\text { (Pasien Baru) }\end{array}$ & $\begin{array}{c}\text { Waktu dilayani } \\
\text { di TPPRJ }\end{array}$ \\
\hline 1 & Responden 1 & 11.09 \\
2 & Responden 2 & 11.00 \\
3 & Responden 3 & 10.35 \\
4 & Responden 4 & 12.41 \\
5 & Responden 5 & 14.51 \\
6 & Responden 6 & 13.02 \\
\hline \multicolumn{3}{c}{ Rata-rata waktu } \\
\hline
\end{tabular}

pelayanan pasien baru

Sumber: Data Primer 2019.

Tabel 3 merupakan waktu pasien lama dilayani di pendaftaran rawat jalan sesi 2. Hasilnya rata-rata waktu pelayanan pasien lama 11.03 menit. 
Tabel 3.Waktu Pasien Lama dilayani di TPPRJ Sesi $2(n=10)$

\begin{tabular}{ccc}
\hline No & $\begin{array}{c}\text { Responden } \\
\text { (Pasien Lama) }\end{array}$ & $\begin{array}{c}\text { Waktu dilayani di } \\
\text { TPPRJ }\end{array}$ \\
\hline 1 & Responden 1 & 15.20 \\
2 & Responden 2 & 8.50 \\
3 & Responden 3 & 12.50 \\
4 & Responden 4 & 12.06 \\
5 & Responden 5 & 29.39 \\
6 & Responden 6 & 8.06 \\
7 & Responden 7 & 7.43 \\
8 & Responden 8 & 9.02 \\
9 & Responden 9 & 5.10 \\
10 & Responden 10 & 6.00 \\
\hline \multicolumn{3}{c}{ Rata-rata waktu } \\
pelayanan pasien lama
\end{tabular}

Sumber: Data Primer 2019.

Tabel 4 merupakan waktu pasien baru dilayani di pendaftaran rawat jalan sesi 2. Hasilnya rata-rata waktu pelayanan pasien lama 12.06 menit.

Tabel 4.Waktu Pasien Baru dilayani di TPPRJ Sesi $2(n=10)$

\begin{tabular}{ccc}
\hline No & $\begin{array}{c}\text { Responden } \\
\text { (Pasien Baru) }\end{array}$ & $\begin{array}{c}\text { Waktu dilayani } \\
\text { di TPPRJ }\end{array}$ \\
\hline 1 & Responden 1 & 22.48 \\
2 & Responden 2 & 17.42 \\
3 & Responden 3 & 18.04 \\
4 & Responden 4 & 12.08 \\
5 & Responden 5 & 13.49 \\
6 & Responden 6 & 8.58 \\
7 & Responden 7 & 8.36 \\
8 & Responden 8 & 12.12 \\
9 & Responden 9 & 7.01 \\
10 & Responden 10 & 6.48 \\
\hline \multicolumn{3}{c}{ Rata-rata waktu } \\
pelayanan pasien baru & 12.06 \\
Sumber: Data Primer 2019.
\end{tabular}

Pengukuran dilakukan 2 sesi, pada sesi 1 dengan rata-rata waktu melayani pasien lama 6 menit 13 detik sedangkan ratarata waktu melayani pasien baru 12 menit 6 detik. Pada sesi 2 dengan rata-rata waktu melayani pasien lama 11 menit 3 detik sedangkan rata-rata waktu melayani melayani pasien baru 12 menit 6 detik. Dari 2 sesi pengukuran waktu yang dilakukan oleh peneliti rata-rata untuk waktu pasien lama dilayani di pendaftaran rawat jalan 8 menit 44 detik, sedangkan rata-rata untuk waktu pasien baru dilayani di pendaftaran rawat jalan 12 menit 40 detik. Rata-rata waktu saat petugas melayani pasien baru maupun pasien lama masih belum sesuai dengan SPM yang sudah dikeluarkan oleh kementerian kesehatan yaitu dengan standar waktu untuk melayani pasien baru kurang lebih 7 menit dan standar waktu untuk melayani pasien lama kurang lebih 5 menit.

Waktu tunggu merupakan masalah yang sering menimbulkan keluhan pasien di beberapa instansi kesehatan. Lama waktu tunggu pasien mencerminkan Puskesmas mengelola komponen yang disesuaikan dengan situasi dan harapan pasien. ${ }^{8}$ Waktu tunggu pendaftaran lama disebabkan terjadinya antrian panjang. Antrian disebabkan oleh kebutuhan akan layanan melebihi kemampuan (kapasitas) pelayanan atau fasilitas layanan, sehingga pengguna fasilitas yang datang tidak bisa segera mendapat layanan disebabkan kesibukan layanan. Antrian sering terjadi karena ketersediaan petugas pada bagian pendaftaran kurang dan waktu antar kedatangan pasien lebih cepat daripada waktu pelayanan. $^{2}$

Berdasarkan hasil penelitian, faktor penyebab lama waktu tunggu pendaftaran yaitu pasien pasien lupa membawa kartu identitas. Faktor lain penyebab lama waktu 
tunggu dikarenakan komputer error, jaringan off-line, dokumen rekam medis yang tidak ditemukan dalam rak filing, dan waktu tunggu pasien yang lama akan berpengaruh pada pasien berikutnya. ${ }^{11}$ Hasil penelitian didapatkan bahwa di ruang tunggu pendaftaran sebuah Rumah Sakit di Kota Sukoharjo menemukan 41 responden dengan waktu tunggu pendaftaran cepat maka sebagian besar pasien merasa puas dengan pelayanan. ${ }^{12}$

Hasil penelitian waktu tunggu pelayanan di rawat jalan RSUD dr. Doris Sylvanus Palangkaraya yang terbanyak yaitu tidak baik (>60 menit) sebanyak 159 orang $(79,9 \%) .{ }^{13}$ Hal tersebut akan berpengaruh terhadap lamanya waktu tunggu dari kedua hal tersebut yaitu pelayanan pasien baru dan lama belum sesuai dengan SPM yang ditetapkan oleh Permenkes nomor 129/MenKes/SK/II/2008 tentang SPM.

\section{KESIMPULAN}

Pengukuran dilakukan 2 sesi dengan hasil pada sesi 1 dengan rata-rata waktu melayani pasien lama 6 menit 13 detik sedangkan rata-rata waktu melayani pasien baru 12 menit 6 detik. Pada sesi 2 dengan rata-rata waktu melayani pasien lama 11 menit 3 detik sedangkan rata-rata waktu melayani melayani pasien baru 12 menit 6 detik.

Berdasarkan hasil ini dapat disimpulkan bahwa mutu pelayanan rata-rata waktu saat petugas melayani pasien baru maupun pasien lama masih belum sesuai dengan SPM yang sudah dikeluarkan oleh Kementerian Kesehatan.

Disarankan bagi Petugas Puskesmas, sebaiknya petugas lebih memperhatikan lamanya waktu tunggu dengan bekerja lebih cepat dan tepat sesuai SOP agar pasien senantiasa merasa puas terhadap mutu pelayanan yang sudah diberikan oleh petugas.

\section{TERIMA KASIH}

1. Dr. Guruh Fajar Shidik S.Kom., M.Cs, selaku Dekan Fakultas Kesehatan Universitas Dian Nuswantoro Semarang, yang telah memberikan kesempatan izin dalam pelaksanaan penelitian ini.

2. dr. Abdul Hakam selaku Kepala Dinas Kesehatan Kota Semarang, yang telah memberikan izin kepada kami untuk memakai Puskesmas Ngaliyan guna melakukan penelitian.

3. Sri Sulastri, Amd. PK, selaku Penanggung Jawab Unit Rekam Medis di Puskesmas Ngaliyan Semarang, yang telah bersedia membimbing dan mengarahkan dalam proses pengambilan data.

\section{KEPUSTAKAAN}

1. Nugraheni, R. Gambaran Waktu Tunggu Pasien dan Mutu Pelayanan Rawat Jalandi Poli Umum UPTD Puskesmas Pesantren 1 Kota Kediri Tahun 2017. Jurnal Wiyata Penelitian Sains dan Kesehatan.16Desember 2017; Volume 4, (2), Hal. 165-172. 
2. Maulana, D., Tamrin, R., Alim, A., Imran, A. Analisis Hubungan Waktu Tunggu Terhadap Kepuasan Pasien Pada Puskesmas Maccini Sombala. Jurnal Kesehatan.30 Oktober 2019; Volume 12, (2), Hal. 99-110.

3. Handayani, S. Tingkat Kepuasan Pasien Terhadap Pelayanan Kesehatan di Puskesmas Baturetno. Profesi (Profesional Islam): Media Publikasi Penelitian.20 Januari 2016;Volume 14,(1), Hal. 42-48.

4. Hasan. Hubungan Waiting Times/Waktu Tunggu dengan Kepuasan Pasien di Poliklinik Mata pada Instalasi Rawat Jalan di RSUD Tarakan Propinsi Kalimantan Timur Tahun 2013. Skripsi.Makassar: Program Studi IImu Keperawatan Fakultas Kedokteran Universitas Hasanuddin; 2014.

5. Handayani, T.,Pujihastuti, A. Waktu Tunggu Pelayanan Pasien Jaminan Kesehatan Nasional (JKN) Rawat Jalan. Jurnal Rekam Medis.Oktober 2017; Volume 11, (2), Hal. 161-171.

6. Rohana, A., Sriatmi, A., Budiyanti, R.T. Pelaksanaan Pelayanan Neonatal Berdasarkan Standar Pelayanan Minimal Kesehatan Bayi Baru Lahir Di Puskemas Dukuhseti Kabupaten Pati. Jurnal Kesehatan Masyarakat (e-Journal). 1 Januari 2020; Volume 8, (1), Hal. 97106.

7. Yovita, M., Khasanah, U., Chaerunnisah, R. Gambaran Waktu Penyediaan Dokumen Rekam Medis di Puskesmas Karang Pule Kota Mataram. Jurnal Rekam Medis dan Informasi Kesehatan. Oktober 2019; Volume 2, (2), Hal. 53-59.

8. Pratiwi, M.R., Sani, F.N. Hubungan Waktu Tunggu Pelayanan Terhadap Tingkat Kepuasan Pasien di Poliklinik Kebidanan dan Kandungan RSUD Kota Surakarta. Profesi (Profesional Islam): Media Publikasi Penelitian.Pebruari 2017; Volume14,(2), Hal. 24-30.

9. Mayasari, F. Analisis Hubungan Waktu Pelayanan dan Faktor Total Quality Service Terhadap Kepuasan Pasien di Poliklinik Kebidanan dan Kandungan RSIA Anugerah Medical Centre Kota Metro Tahun 2015. Jurnal Administrasi
Rumah Sakit Indonesia.Maret 2016; Volume 2, (3), Hal. 214-230.

10. Notoatmodjo, S. Metodologi Penelitian Kesehatan. Yogyakarta: Rineka Cipta; 2016.

11. Dewi, M. Pengaruh Kualitas Pelayanan terhadap Kepuasan Pasien Pengguna BPJS pada Rumah Sakit Rehabilitasi Medik Kabupaten Aceh Timur. Jurnal Manajemen dan Keuangan.Pebruari 2016; Volume 5, (2), Hal. 535-544.

12. Dewi, A.U., Astuti, R., Werdani, K.E. Hubungan Waktu Tunggu Pendaftaran Dengan Kepuasaan Pasien Di Tempat Pendaftaran Pasien Rawat Jalan (TPPRJ) RSUD Sukoharjo. Artikel Penelitian. Maret 2015; Volume 1, (1), Hal. 1-13.

13. Ernawati, E., Pertiwiwati, E., Setiawan, $\mathrm{H}$. Waktu Tunggu Pelayanan Rawat Jalan Dengan Tingkat Kepuasan Pasien (Studi Penilitian Di RSUD Dr. Doris Sylvanus Palangkaraya). Nerspedia. April 2018; Volume 1, (1), Hal. 1-10. 